\title{
Esomeprazole improves the acidic microenvironment of epithelial ovarian cancer by inhibiting the expression of V- ATPase
}

\author{
Yasong Chi, Ruiqin Yue, Yanru Lv, Wei Liao, Ruchang Yin* \\ Department of Gynecology, Liaocheng Second People's Hospital, Linqing, PR China \\ *For correspondence: Email: brc91c@163.com \\ Sent for review: 19 May 2020 \\ Revised accepted: 27 July 2020
}

\begin{abstract}
Purpose: To determine the effect of esomeprazole on apoptosis of ovarian cancer cells and their sensitivity to paclitaxel, and the underlying mechanism.

Methods: Human ovarian paclitaxel-resistant cancer cells were cultured in vitro, and treated with esomeprazole at doses of 50, 100 and $250 \mathrm{~mol} / \mathrm{L}$. Cell proliferation was determined using MTT assay. Paclitaxel-resistant cells were divided into control group, esomeprazole group, paclitaxel group, and esomeprazole + taxol group. Western blot was employed for the assay of protein levels of bcl-2, Bcl-xl, $P$-gp and V-ATPase, while BCECF-AM method was employed to determine changes in intracellular $\mathrm{pH}$. Results: Esomeprazole significantly inhibited the proliferation of paclitaxel-resistant cells in a dosedependent manner. The half-maximal inhibitory concentration (IC50) value of esomeprazole + paclitaxel was significantly low, when compared with those of the other treatments $(p<0.05)$. Apoptosis was significantly higher in esomeprazole + paclitaxel group than in any other treatment group $(p<0.05)$. The expressions of $\mathrm{Bcl}-2$ and P-gp in esomeprazole + paclitaxel group decreased significantly, relative to the corresponding values for other groups, while protein expression of bcl-xl was markedly increased. The intracellular $\mathrm{pH}$ value of esomeprazole + paclitaxel group was significantly lower than those for other treatment groups $(p<0.05)$.

Conclusion: Esomeprazole improves the acidic microenvironment of epithelial ovarian cancer by inhibiting the expression of V-ATPase, and restores the sensitivity of ovarian cancer cells to paclitaxel by inhibiting their proliferation and apoptosis. This revelation may explain patients' resistance to paclitaxel.
\end{abstract}

Keywords: Esomeprazole, V-ATPase, Apoptosis, Ovarian cancer, Taxol, Sensitivity

\begin{abstract}
This is an Open Access article that uses a fund-ing model which does not charge readers or their institutions for access and distributed under the terms of the Creative Commons Attribution License (http://creativecommons.org/licenses/by/4.0) and the Budapest Open Access Initiative (http://www.budapestopenaccessinitiative.org/read), which permit unrestricted use, distribution, and reproduction in any medium, provided the original work is properly credited.
\end{abstract}

Tropical Journal of Pharmaceutical Research is indexed by Science Citation Index (SciSearch), Scopus, International Pharmaceutical Abstract, Chemical Abstracts, Embase, Index Copernicus, EBSCO, African Index Medicus, JournalSeek, Journal Citation Reports/Science Edition, Directory of Open Access Journals (DOAJ), African Journal Online, Bioline International, Open-J-Gate and Pharmacy Abstracts

\section{INTRODUCTION}

Ovarian cancer accounts for the highest mortality among gynecological tumors, second only to cervical cancer and uterine body cancer. Epithelial ovarian cancer-associated mortality is the highest amongst all gynecological tumors. The tumor, which is most common in postmenopausal women, does not present any obvious symptoms in the early stage, but shows abdominal distension, abdominal pain and wasting in the late stage [1]. 
The pathogenesis of ovarian cancer is not yet clear, although it is thought that it involves mostly genetic and endocrine factors. Due to the insidious onset of ovarian cancer and the lack of typical clinical symptoms, most of the patients are usually diagnosed with distant metastasis, and so lose the opportunity to benefit from surgical treatment. At present, several combination chemotherapy schemes are used in clinical practice for treating the disease. Although some degree of clinical efficacy has been achieved, resistance to chemotherapy has remained the key cause of low long-term survival of ovarian cancer patients [2].

In recent years, studies have found that all drugresistant cell lines have increased intracellular $\mathrm{pH}$ and lower $\mathrm{pH}$ outside the cell, and the acidic environment of the tumor cells decreases the ability of alkaline chemotherapy drugs to penetrate the cell membrane, thereby resulting in drug-resistant tumor cells. The hollow bubble type proton pump (V- ATPase) plays an important role in the maintenance of acidic microenvironment in tumors [3, 4]. Studies have shown that proton pump inhibitors significantly inhibit V-ATPase activity, promote tumor cell apoptosis, and enhance sensitivity of tumor cells to chemotherapy [5]. Esomeprazole is a popular non-specific V-ATPase inhibitor. The purpose of this study was to investigate the effect of inhibition of V-ATPase on the apoptosis and sensitivity of ovarian cancer cells to paclitaxel.

\section{EXPERIMENTAL}

\section{Reagents and instruments}

Human ovarian cancer cell line (paclitaxelresistant cell line) was purchased from Shanghai Yanjing Biotechnology Co. Ltd. Esomeprazole was product of Astrazeneca Pharmaceuticals Ltd, while Taxol was purchased from Jiangsu Osaikang Pharmaceutical Co. Ltd. RPMI160, DMEM culture medium, and $0.25 \%$ trypsin containing EDTA were purchased from Hyclone, USA. TRIzol was purchased from Shanghai Terui Biological Engineering Co. Ltd. Antibody against V-ATPase was obtained from Santa Cruz Company, United States, while BCA protein quantitative assay kit was purchased from Biyuntian Institute of Technology.

Optical microscopes were products of Olympus, Japan. Super clean worktable was purchased from Beijing Semiconductor Equipment no. 1 Plant. Gel imager was obtained from Shanghai Tanon Company. Instrument for RT-PCR and pipettes were purchased from Eppendorf, Germany. Low-temperature, high-speed centrifuge was purchased from Sigma Company. Enzyme marker was bought from Thermo Fisher Technology Co. Ltd, while Flow cytometer was product of Becton Dikinson, USA.

\section{Cell culture}

The cells were cultured in RPMI 1640 containing $10 \%$ fetal bovine serum at $5 \% \mathrm{CO}_{2}$ and saturated humidity at $37{ }^{\circ} \mathrm{C}$. Cells at logarithmic growth phase were selected for the studies. The cell lines were divided into control group maintained in culture medium only, esomeprazole group cultured in medium containing $150 \mathrm{~mol} / \mathrm{L}$ esomeprazole, paclitaxel group cultured in a medium containing $2 \mathrm{~mol} / \mathrm{L}$ paclitaxel, and esomeprazole + paclitaxel group, in which the culture medium contained $150 \mathrm{~mol} / \mathrm{L}$ esomeprazole and $2 \mathrm{~mol} / \mathrm{L}$ paclitaxel.

\section{Determination of cell proliferation}

The effect of each treatment on cell proliferation was determined using MTT assay. Cells at exponential growth phase $(200 \mu \mathrm{L})$ were inoculated in 96-well plates at a density of $5 \mathrm{x}$ $10^{3}$ cells/well. Three replicate wells were used for each treatment. After $24 \mathrm{~h}, 20 \mu \mathrm{L}$ MTT solution was added to each well, followed by incubation in the dark for $4 \mathrm{~h}$. Thereafter, the medium was replaced with DMSO $(150 \mu \mathrm{L})$ to solubilize the resultant formazan crystals. After shaking for 5 $10 \mathrm{~min}$, the absorbance of each well was read at $490 \mathrm{~nm}$. The \% inhibition of proliferation was calculated as shown in Eq 1.

$\mathrm{CPI}(\%)=\left[1-\left(\mathrm{Abs}_{\mathrm{exp}}-\mathrm{Abs} \mathrm{s}_{\mathrm{bc}}\right) \times 100\right] / \mathrm{Abs}_{\mathrm{nc}}$ (1)

where $A b s_{\text {exp }}, A b s_{b c}$ and $A b s_{n c}$ are the absorbance values of the experimental group, blank control and negative control group, respectively, while $\mathrm{CPI}$ is cell proliferation inhibition. The $\mathrm{IC}_{50}$ value for each treatment was calculated from the $\%$ inhibition.

\section{Assessment of protein expressions of $\mathrm{Bcl}-2$, the $\mathrm{Bcl}-\mathrm{xl}, \mathrm{P}$-gp and V-ATPase}

Western blot method was used for assay of protein expressions of $\mathrm{Bcl}-2$, the Bcl-xl, P-gp. Total protein was extracted, and the protein was quantified using BCA method. The protein from each treatment was subjected to SDSpolyacrylamide gel electrophoresis, followed by transfer of the bands to polyvinylidene membrane, blocking of non-specific binding, and incubation with primary antibodies for Bcl-2, the Bcl-xl, P-gp and V-ATPase. This was followed by incubation with secondary antibody at room 
temperature overnight. The gene for GAPDH served as housekeeping gene. Quantity One software was used to calculate the gray values of each strip for analysis.

\section{Determination of changes in intracellular $\mathrm{pH}$}

The BCECF-AM method was to measure changes in intracellular $\mathrm{pH}$. Cells at exponential growth phase were seeded in 6-well plates at a density of $1.0 \times 10^{4}$ cells/well. Following the various treatments, the cells were washed with FBS, followed by washing with once with the culture medium without bicarbonate and FBS. Then, the cells were incubated with $1 \mu$ of BCECF-AM for $40 \mathrm{~min}$ in the dark. The green fluorescence intensity of the cells was observed under an immunofluorescence microscope.

\section{Statistical analysis}

Results are expressed as mean \pm SD. Twogroup comparisons were carried out using $t$-test, while multiple-group comparisons were done with repeated measurement ANOVA. Statistical significance was assumed at $p<0.05$. All statistical analyses were carried out with SPSS 21.0 software.

\section{RESULTS}

\section{Effect of esomeprazole treatment on cell} proliferation

Treatment of taxol-resistant cells with 50, 100 and $250 \mathrm{~mol} / \mathrm{L}$ esomeprazole resulted in significant and dose-dependent inhibition of their proliferation, as shown in Figure 1. Further experiments on the sensitization effect of esomeprazole to chemotherapy showed that the $\mathrm{IC}_{50}$ of esomeprazole + paclitaxel was significantly lower than the $\mathrm{IC}_{50}$ associated with any of the other treatments $(p<0.05$; Table 1$)$.

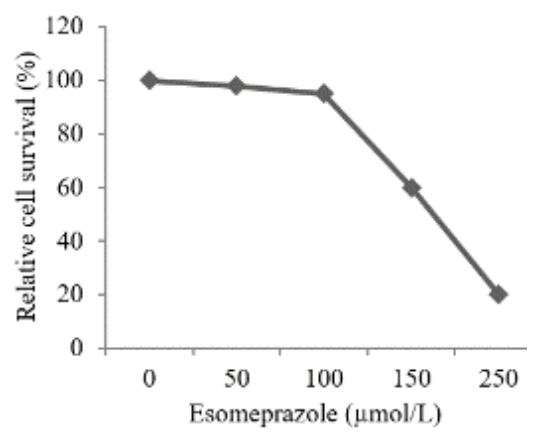

Figure 1: Effect of esomeprazole at different concentrations on cell proliferation
Table 1: Effect of esomeprazole + taxol treatment on cell proliferation $(n=5)$

\begin{tabular}{lc}
\hline Group & $\mathbf{I C}_{50}$ \\
\hline Control & $10.16 \pm 1.68$ \\
Esomeprazole & $8.12 \pm 1.45^{\star}$ \\
Taxol & $8.62 \pm 1.33^{*}$ \\
Esomeprazole + taxol & $2.12 \pm 0.45^{\star \#}$ \\
\hline${ }^{*} P<0.05$, vs control; ${ }^{\#} p<0.05 ;$ vs esomeprazole \\
group paclitaxel groups
\end{tabular}

\section{Effect of esomeprazole + paclitaxel combined treatment on apoptosis}

The \% apoptosis in the esomeprazole + paclitaxel group was significantly higher than that in any other treatment group $(p<0.05)$. Western blot results showed that the expressions of bcl-2 and P-gp in esomeprazole + paclitaxel group were markedly low, when compared to those in other treatments, but protein expression of $\mathrm{Bcl}-\mathrm{xl}$ was markedly increased. These results are presented in Table 2 and Figure 2.

Table 2: Effect of esomeprazole + paclitaxel combination apoptosis $(n=5)$

\begin{tabular}{lc}
\hline Group & Apoptosis (\%) \\
\hline Control & $5.46 \pm 1.23$ \\
Esomeprazole & $8.20 \pm 2.89^{*}$ \\
Taxol & $8.15 \pm 3.24^{*}$ \\
Esomeprazole + & $27.86 \pm 5.45^{\star \#}$ \\
taxol group & \\
\hline${ }^{\star} P<0.05$, vs control; ${ }^{\#} p<0.05 ;$ vs esomeprazole and \\
paclitaxel groups
\end{tabular}

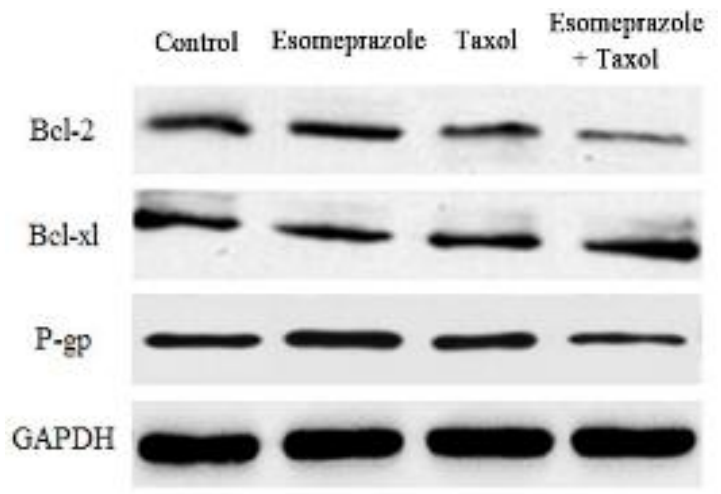

Figure 3: Influence of esomeprazole + taxol combination treatment on expressions of apoptotic proteins and drug-resistant proteins

\section{Effect of esomeprazole + taxol combination treatment on intracellular $\mathrm{pH}$}

The intracellular $\mathrm{pH}$ value of esomeprazole + paclitaxel group was markedly low, relative to that of each of other groups, as shown in Table 3. 
Table 3: Effect of esomeprazole + taxol combined treatment on intracellular $\mathrm{pH}$

\begin{tabular}{ll}
\hline Group & $\mathbf{p H}$ \\
\hline Control & $10.41 \pm 2.01$ \\
Esomeprazole & $7.2 \pm 1.16^{*}$ \\
Taxol & $7.15 \pm 1.22^{*}$ \\
Esomeprazole + Taxol & $6.80 \pm 1.02^{* \#}$ \\
\hline${ }^{*} P<0.05$, vs control; ${ }^{\#} p<0.05 ;$ vs esomeprazole and \\
paclitaxel groups
\end{tabular}

Effect of esomeprazole + taxol combination treatment on the expression of V-ATPase in cells

The protein expression of V-ATPase in drugresistant cells was markedly higher than that in sensitive cells, and the combined treatment with esomeprazole and paclitaxel significantly reduced the expression of V-ATPase protein in cells, when compared with paclitaxel monotherapy group. These results are shown in Figure 4.

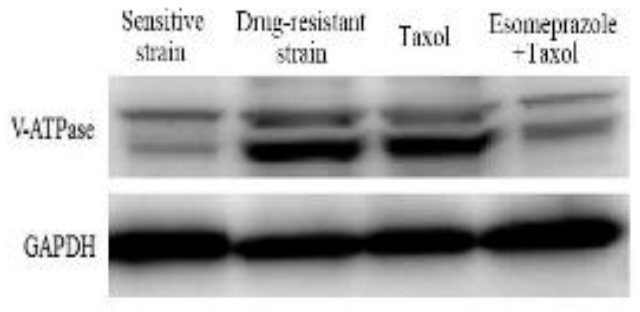

Figure 4: Effect of esomeprazole + Taxol combined treatment on V-ATPase expression

\section{DISCUSSION}

Ovarian cancer is associated with the highest mortality of all gynecological tumors. Since the ovary is within the pelvic cavity, lesions are not easily detected timely, leading to diagnosis of 70 $\%$ of patients at the advanced stage of the disease. In patients with epithelial ovarian cancer, extensive tumor cell reduction and adjuvant chemotherapy are the basic treatment strategies. This is so because tumors often metastasize widely in the pelvic cavity, especially small cancer foci which can hardly be seen by the naked eye, thereby necessitating the use of adjuvant chemotherapy [6,7]. At present, platinum-based combined chemotherapy is used in clinical treatment of advanced ovarian cancer.

However, most patients develop drug resistance. The resistance of malignant tumors to anticancer drugs adversely affects clinical treatment efficacy [8]. In recent years, some scholars have established a close relationship between high acidity of the extracellular microenvironment of tumor cells and tumor drug resistance, with intracellular alkalinity and extracellular acidity, implying reversal of $\mathrm{pH}$ gradient. Alterations in $\mathrm{pH}$ gradient are effective in reversing drug resistance. Indeed, proton pump inhibitors, as antacids, achieve reversal of insensitivity to chemotherapy drugs by inhibiting the proton pump and blocking the acidification of the microenvironments of tumor cells [9]. Esomeprazole, an optical isomer of proton pump inhibitor, readily attains high plasma concentration, with high bioavailability and strong inhibitory capacity for acidity. In addition, it is associated with low resistance and minimal adverse reactions $[10,11]$.

One of the most-studied $\mathrm{pH}$ regulatory pumps in cells in recent years is V-ATPase. It is widely distributed in the cytoplasmic membrane of eukaryotic cells and the membrane system of cell vesicles, and it participates in membrane transport, acid secretion and other cellular activities [12]. Intracellular acidification induces cell apoptosis: V-ATPase enhances regulation of transmembrane $\mathrm{pH}$, and its overexpression decreases apoptosis, and enhances the invasion and spread of tumor cells, as well as multi-drug resistance [13].

Previous studies have demonstrated that the use of V-ATPase inhibitors suppresses the proliferation of tumor cells and promotes cell apoptosis [14]. Studies have also shown that proton pump inhibitors dehydrate and combine with V-ATPase to form irreversible covalent disulfide bonds, thereby inhibiting the enzyme, blocking acid secretion, and reversing drug resistance of a variety of tumor cells [15-17].

In this study, the $\mathrm{IC}_{50}$ value of esomeprazole + paclitaxel was significantly low, when compared with the other groups, and apoptosis in the omeprazole + Taxol group was higher than that of any other treatment. The expressions of $\mathrm{Bcl}-2$ and P-gp in esomeprazole + paclitaxel group were significantly lower than those in any other treatment groups; the $\mathrm{Bcl}-\mathrm{xl}$ protein expression significantly increased, while intracellular $\mathrm{pH}$ was significantly lower than that in any of other treatment group. The protein expression of $\mathrm{V}$ ATPase in drug-resistant cells was markedly higher than that in sensitive cells, and the combined treatment with esomeprazole and paclitaxel significantly reduced the expression of V-ATPase protein in cells, when compared with paclitaxel monotherapy group. These results clearly suggest that esomeprazole may reverse tumor acidification by inhibiting the expression of V-ATPase. 


\section{CONCLUSION}

Esomeprazole improves the acidic microenvironment of epithelial ovarian carcinoma cells by inhibiting V-ATPase expression, and it restores sensitivity of ovarian cancer cells to paclitaxel by inhibiting their proliferation and apoptosis. This discovery may solve patients' resistance to paclitaxel.

\section{DECLARATIONS}

\section{Conflict of interest}

No conflict of interest is associated with this work.

\section{Contribution of authors}

We declare that this work was done by the author(s) named in this article and all liabilities pertaining to claims relating to the content of this article will be borne by the authors. All authors read and approved the manuscript for publication. Ruchang Yin conceived and designed the study, Yasong Chi, Ruiqin Yue, Yanru Lv, Wei Liao, Ruchang Yin collected and analysed the data, while Yasong Chi wrote the manuscript.

\section{Open Access}

This is an Open Access article that uses a funding model which does not charge readers or their institutions for access and distributed under the terms of the Creative Commons Attribution License (http://creativecommons.org/licenses/by/ 4.0) and the Budapest Open Access Initiative (http://www.budapestopenaccessinitiative.org/rea d), which permit unrestricted use, distribution, and reproduction in any medium, provided the original work is properly credited.

\section{REFERENCES}

1. Young RH. Ovarian sex cord-stromal tumours and their mimics. Pathol 2018; 50(1): 5-15.

2. Pavlovic A, Glavina Durdov M, Lozic D, Skare Librenjak $L$, Alfirevic $D$. Primary ovarian lymphoma and benign Brenner tumor. Taiwan J Obstet Gynecol 2016; 55(1): 138-139.

3. Kissing $S$, Rudnik S, Damme M, Lüllmann-Rauch R, Ichihara A, Kornak U, Eskelinen EL, Jabs S, Heeren J, De Brabander JK, et al. Disruption of the vacuolar-type, ATPase complex in liver causes MTORC1-independent accumulation of autophagic vacuoles and lysosomes. Autophagy 2017; 13(4): 670-685.
4. Wódkiewicz M, Chwedorzewska KJ, Bednarek PT, Anna Znój, Androsiuk P, Galera H. How much of the invader's genetic variability can slip between our fingers? A case study of secondary dispersal of Poa annua on King George Island (Antarctica). Ecol Evol 2018; 8(1): 592600.

5. Gölz JP, Bockelmann S, Mayer K, Steinhoff HJ, Wieczorek $H$, Huss M, Klare JP, Menche D. EPR Studies of V-ATPase with Spin-Labeled Inhibitors DCC and Archazolid: Interaction Dynamics with Proton Translocating Subunit c. ChemMedChem 2016; 11(4): 420-428.

6. Pashankar F, Hale JP, Dang H, Krailo M, Brady WE, Rodriguez-Galindo C, Nicholson JC, Murray MJ, Bilmire $D F$, Stoneham $S$, et al. Is adjuvant chemotherapy indicated in ovarian immature teratomas $A$ combined data analysis from the Malignant Germ Cell Tumor International Collaborative. Cancer 2016; 122(2): 230237.

7. Han Y, Li S, Wu L, Zhang X, Cao D. Non-Peutz-Jeghers syndrome-associated ovarian sex cord tumor with annular tubules: Report of a malignant case. J Obstet Gynaecol Res 2016; 42(2): 224-227.

8. Elhfnawy AM, Bieber M, Schliesser M, Kraft P. Atypical presentation of giant cell arteritis in a patient with vertebrobasilar stroke: A case report. Med 2019; 98(32): 16737.

9. Varghese $S$, Halling PJ, Häussinger D, Wimperis S. Twodimensional $1 \mathrm{H}$ and $1 \mathrm{H}$-detected NMR study of a heterogeneous biocatalyst using fast MAS at high magnetic fields. Solid State Nucl Magn Reson 2018; 92 : 7-11.

10. Tai WC, Liang CM, Kuo CM, Huang PY, Wu CK, Yang SC, Kuo YH, Lin MT, Lee CH, Hsu CN, et al. A 14 day esomeprazole- and amoxicillin-containing high-dose dual therapy regimen achieves a high eradication rate as first-line anti-Helicobacter pylori treatment in Taiwan: a prospective randomized trial. J Antimicrob Chemother 2019; 74(6): 1718-1724.

11. Song ZQ, Zhou LY. Esomeprazole, minocycline, metronidazole and bismuth as first-line and second-line regimens forlr, Helicobacter pylorilr, eradication. J Dig Dis 2016; 17(4): 260-267.

12. Hiasa M, Okui T, Allette YM, Ripsch MS, Sun-Wada GH, Wakabayashi $H$, Roodman GD, White FA, Yoneda $T$. Bone Pain Induced by Multiple Myeloma Is Reduced by Targeting V-ATPase and ASIC3. Cancer Res 2017; 77(6): 1283-1295.

13. Bodzęta A, Kahms M, Klingauf J. The Presynaptic VATPase Reversibly Disassembles and Thereby Modulates Exocytosis but Is Not Part of the Fusion Machinery. Cell Rep 2017; 20(6): 1348-1359.

14. Kim D, Hwang HY, Kim JY, Lee JY, Yoo JS, MarkoVarga G, Kwon HJ. FK506, an Immunosuppressive Drug, Induces Autophagy by Binding to the V-ATPase Catalytic Subunit A in Neuronal Cells. J Proteome Res 2017; 16(1): 55-64.

Trop J Pharm Res, August 2020; 19(8): 1589 
15. Tognon E, Kobia F, Busi I, Fumagalli A, De Masi F, Vaccari T. Control of lysosomal biogenesis and Notchdependent tissue patterning by components of the TFEB-V-ATPase axis in Drosophila melanogaster. Autophagy 2016; 12(3): 499-514.
16. Xiao F, Mao J. Treatment of gastroesophageal refluxrelated cough with proton pump inhibitors and prokinetic agents. Acta Medica Mediterr 2019; 35(6): 3131-3137.

17. Dilci A, Cevizci R. Is gastroesophageal reflux a possible etiologic factor for itchy ear canal? Acta Medica Mediterr 2019; 35(1): 77-80. 